obtain best value for money. Naturalistic trials are needed to address the problem of different approaches to treatment seen in clinical trials and clinical practice.

\section{References}

Beasley, C. M., Tollefson, G. D.. Tran, P. V., et al (1996a) Olanzapine versus placebo and haloperidol. Acute phase results of the North American double-blind olanzapine trial. Neuropsychopharmacology. 14. 111-123.

- SANGer, T., SATTERleE, W., et al (1996b) Olanzapine versus placebo: results of a double-blind. fixed-dose olanzapine trial. Psychopharmacology. 124, 159-167.

Tollefson, G. D.. Beasley, C. M., TRAN, P. V.. et al (1997a) Olanzapine versus haloperidol in the treatment of schizophrenia and schizoaffective and schizophreniform disorders: results of an international collaborative trial. American Journal of Psychiatry. 164. 457-465.

-, - TAMURA, R. N., et al (1997b) Blind, controlled, longterm study of the comparative incidence of treatmentemergent tardive dyskinesia with olanzapine or haloperidol. American Journal of Psychiatry. 154. 1248-1254.

*David Taylor, Chief Pharmacist, Maudsley Hospital, Denmark Hill, London SE5 8AZ; Siobhan Drummond. Pharmacist, Chelsea and Westminster Hospital, London; and Joanne Pendlebury, Pharmacist, Charing Cross Hospital, London

*Correspondence

\title{
Attendance at child psychiatry clinics
}

\section{Comparison with attendance at child medical and surgical clinics}

\author{
Selim M. El-Badri and Paul McArdle
}

\begin{abstract}
A widespread perception exists that attendance at child psychiatry clinics is especially poor. The reported rate of non-aftendance at a child psychiatiy outpatient clinic is $61 \%$. However, other child health clinics also suffer a high rate of non-attendance. In this paper we examine the hypothesis that rates of non-attendance are higher in child psychiatry than in other child health out-patient clinics.
\end{abstract}

Previous studies have suggested that non-attendance and poor clinic compliance is a common problem in child health services and children clinics (Cooper \& Lynch, 1979; Novick et al, 1981: Gould et al, 1985; Potter \& Darwish. 1996). Some authors have suggested that there may be special factors influencing attendance at child psychiatric clinics. These include parental expectations of treatment offered (Plunkett, 1984), disadvantageous family structure, and the characteristics of presenting problems, especially those with antisocial behaviour (Garralda \& Bailey, 1988). Non-attendance may create inefficiencies for mental health care providers and suffering for children, which may have effects on patients' care and cost-effectiveness. This study therefore investigates whether attendance at child psychiatry clinics is poorer than at other child health clinics.

\section{The study}

Two large city centre general practices known to refer to child psychiatry were approached and their collaboration agreed. These provide services for approximately 25000 Newcastle residents. Data pertaining to patients referred from the two general practitioner practices to (a) a child and adolescent psychiatry unit, (b) ear, nose and throat (ENT) clinic and (c) a general paediatric clinic were obtained. Hospital case 
notes and general practitioner records of all patients $(n=86)$ referred from the two practices to the three hospital services over a period of six months were studied and the information recorded in a structured proforma. Referred cases were identified from visits to the general practices. The proforma covered the following information: socio-demographic data; specific data concerning attendance/non-attendance at the clinic; nature of the clinical problem and its extent; and, in order to evaluate the impact on attendance of different waiting-list times, the length of time lapsed between referral and appointment. The rate of attendance among children and families referred to child psychiatry clinic was compared with the rate of attendance of referred children and families to ENT and paediatric clinics.

\section{Findings}

The demographic characteristics of patients are shown in Table 1. There were no significant differences in gender ratio between the three groups and there was no significant difference in delay prior to first consultation. However, child psychiatry patients were significantly older than those attending other clinics. Also, child psychiatry patients were significantly less likely than paediatric patients to be living with two biological parents.

In the child and adolescent psychiatry group, $12(48 \%)$ had neurotic problems, $3(12 \%)$ had conduct problems and $8(32 \%)$ presented with mixed neurotic and conduct difficulties. In $2(8 \%)$ of this group, the diagnoses were uncertain due to lack of adequate information. Of the referred patients, $13(52 \%)$ in this group had presenting problems which were confined only to home, and $6(24 \%)$ of them had problems that involved their schools as well.

In the psychiatric group, neurotic problems were over-represented in children with two parents as opposed to conduct difficulties in children with single parents. This is consistent with literature evidence that conduct disorders are more frequent among children from broken homes.

Attendance in the three groups is shown in Table 2. There was no difference in rates of initial attendance between the three groups. There was a trend for a higher rate of subsequent nonattendance in the child psychiatry than in either of the other two groups. Similarly, a somewhat smaller proportion of child psychiatry patients completed treatment. However, findings were not statistically significant. There were greater numbers of conduct and behä joural problem patients who defaulted follow-'sp than patients with neurotic problems, but the difference was not statistically significant.

\section{Comment}

Child psychiatry patients show a high rate of attendance at first assessment interviews.

Table 1. Demographic characteristics of patients

\begin{tabular}{llll}
\hline & $\begin{array}{l}\text { Child and adolescent } \\
\text { psychiatry patients } \\
(\boldsymbol{n}=25)\end{array}$ & $\begin{array}{l}\text { Ear, nose and throat } \\
\text { pationts } \\
(\boldsymbol{n}=28)\end{array}$ & $\begin{array}{l}\text { General paediatric } \\
\text { pationts } \\
(\boldsymbol{n}=33)\end{array}$ \\
\hline Male:female ratio & $12: 13$ & $10: 17$ & $15: 18$ \\
Mean age' & 10.96 & 7.11 & 4.94 \\
Two parents & $7(28 \%)$ & - & $18(54.5 \%)$ \\
Other family structure & $13(52 \%)$ & - & $4(12.1 \%)$ \\
Missing family structure data & $5(20 \%)$ & $28(100 \%)$ & $11(33.3 \%)$ \\
\hline
\end{tabular}

1. One way ANOVA test indicating significant mean age difference $(P<0.0001)$

2. $\chi^{2}<0.05$.

Table 2. Attendance of general practitioner referred patients at three hospital child health clinics

\begin{tabular}{lccc}
\hline & $\begin{array}{l}\text { Child and adolescent } \\
\text { psychiatry patients }\end{array}$ & $\begin{array}{l}\text { Ear, nose and throat } \\
\text { pationts }\end{array}$ & $\begin{array}{l}\text { General paediatric } \\
\text { pationts }\end{array}$ \\
\hline Initial non-attendance & $1(4 \%)$ & $2(7.1 \%$ & $1(3 \%)$ \\
Failed to attend subsequent & $7(28 \%)$ & $1(3.6 \%)$ & $1(3 \%)$ \\
$\begin{array}{l}\text { appointments } \\
\text { Completed treatment }\end{array}$ & $13(52 \%)$ & $19(67.9 \%)$ & $22(66.7 \%)$ \\
Missing data & $4(16 \%)$ & $6(21.4 \%)$ & $9(27.3 \%)$ \\
\hline
\end{tabular}


However, attendance may subsequently decline at a greater rate than at other paediatric clinics. Of the factors we examined, the high rates of disruptive behaviour disorders in the children of unsupported parents, and the older age of the children, are likely to be relevant. Therefore, the high rate of defaulting from follow-up appointments in the psychiatric patients despite a high rate of attendance at first appointment may be due to parental or child dissatisfaction with the first consultation. However, it may also be due to the greater age of child psychiatry patients, so that their views unlike those of much younger paediatric or ENT patients need to be taken into account by parents. It may also be due to the different family structures of child psychiatry patients so that there is less parental support for further attendance in this group. This is consistent with previous reports that parental separation had no effect on first attendance but significantly increased the rate of defaulting from follow-up appointment (Cottrell et al, 1988).

Children with disruptive behaviour disorders showed the highest rate of non-attendance in this study and are known to default at a high rate from clinics relying on psychological treatments alone (Kazdin, 1990). Future studies need to take into account the effect on clinic attendance of the recent rise in use of medication, especially of stimulant agents for these patients. Clearly a focus on other elements of client satisfaction that influence decisions to attend is required.

Further, while only $4 \%$ of the child psychiatry group did not attend at all, it is inevitable that this leads to failure to investigate such smaller groups of patients and families who do not attend even their initial appointment. This tends to exclude them from such studies. Therefore, in order to identify factors that might contribute to initial and subsequent non-attendance (e.g. the lack of crèche facilities especially for unsupported single parents), larger samples are needed. In this way it may be easier to engage perhaps the most vulnerable referred families and children and maximise efficient and costeffective child psychiatric care.

\section{Acknowledgements}

We thank general practitioners Dr T. McConnell and $\mathrm{Dr} J$. Kelleher for their help in completing this study.

\section{References}

COOPER, N. A. \& LYNCH, M. A. (1979) Lost to follow up. A study of non-attendance at a general paediatric outpatient clinic. Archives of Diseases in Childhood. 65, 765-769.

COTtRel. D., HiLl. P.. WALK. D., et al (1988) Factors influencing non-attendance at child psychiatry outpatient clinics. British Journal of Psychiatry. 152. 201-204.

GaRralda, M. E. \& Balley, D. (1988) Child and family factors associated with referral to child psychiatrists. British Journal of Psychiatry, 153, 81-89.

Gould, M. S., ShafFer, D. \& KAPLAN, D. (1985) The characteristics of dropouts from a child psychiatric clinic. Journal of the American Academy of Child Psychiatry, 24, 316-328.

KAZDIN, A. E. (1990) Premature termination of treatment among children referred for antisocial behaviour. Journal of Child Psychology and Psychiatry. 31. 415425.

Novick, J., Benson, R. \& Rembar, J. (1981) Patterns of termination in an outpatient clinic for children and adolescents. Journal of the American Academy of Child Psychiatry. 20, 834-844.

PLUNKETT. J. W. (1984) Parents treatment expectations and attrition from a child psychiatric service. Journal of Clinical Psychology, 40: 372-377.

POTTER. R. \& DARWISH, A. (1996) Predicting attendance at child and adolescent clinics. Psychiatric Bulletin. 20. 717-718.

*Selim M. El-Badri, Clinical Research Associate, Department of Psychiatry. School of Neurosciences, University of Newcastle upon Tyne, NE1 4LP: and Paul McArdle, Consultant and Senior Lecturer in Child and Adolescent Psychiatry, Fleming Nuffield Unit for Children and Young People, Newcastle upon Tyne

\section{*Correspondence}

